\title{
Fetal Lung Liquid Absorption and Alveolar Epithelial Solute Permeability in Surfactant Deficient, Breathing Fetal Lambs
}

\author{
E. A. EGAN, ${ }^{(23)}$ WILliAM P. DILLON, AND SUSAN ZORN \\ Departments of Pediatrics, Physiology, and Obstetrics and Gynecology, Children's Hospital of Buffalo, Buffalo, \\ New York, USA
}

\begin{abstract}
Summary
The absorption of liquid volume and radiolabeled tracer solutes from the lungs of premature lambs was investigated during the first hours of ventilation. Exteriorized lambs, 133-141 d gestation, with intact umbilical circulation had $\left[{ }^{131} \mathrm{I}\right]$ albumin and $\left[{ }^{125} \mathrm{I}\right]$ cytochrome $\mathrm{C}$ added to the fetal lung liquid before breathing, and, additionally, $\left[{ }^{57} \mathrm{Co}\right]$ cyanocobalamin added to the remaining alveolar liquid after 20,60 , and $120 \mathrm{~min}$ of ventilation. Alveolar liquid was rapidly absorbed from the alveolar space, averaging more than $75 \%$ absorption in the first hour whether they breathed spontaneously or were ventilated. All animals absorbed proteins and water at the same rate as water during the first 20 min of breathing. Older, spontaneously breathing lambs released more surfactant into the alveolar space $(302 \pm 82 \mu \mathrm{M})$ than younger ventilated animals $(92 \pm 32 \mu \mathrm{M})$. After the first $20 \mathrm{~min}$ of breathing, older animals no longer absorbed [ $\left.{ }^{131} \mathrm{I}\right]$ albumin and [25I]cytochrome $C$, and at $4 \mathrm{~h}$ had near normal lung wet:dry weight ratio, $5.7 \pm 0.2$. Younger animals continued to absorb $\left[^{131}\right.$ I]albumin and $\left[^{125} I\right]$ cytochrome $\mathrm{C}$ as rapidly or more rapidly than liquid, and after $4 \mathrm{~h}$ had retained liquid in the lung wet:dry weight ratio $6.3 \pm 0.2$. Alveolar surfactant appears able to alter the solute permeability of ventilated premature lung and the clearance of the fetal liquid from the lungs.
\end{abstract}

The onset of breathing at birth in mammals is accompanied by the absorption of the fetal lung liquid which has distended the fetal airspace. Absorption probably starts during labor $(3,17)$ and total clearance from the interstitium of excess liquid by lung lymphatics and blood takes $4-6 \mathrm{~h}(1,2,10,18)$. In mature lambs, fetal lung liquid absorption from the airspace is facilitated by an increase in the hydraulic conductivity and small solute permeability of the lining epithelium during the first hours of breathing (6). Sodium transport may also be an important mechanism for alveolar liquid clearance (16).

Knowledge of lung liquid absorption at birth in premature mammals is limited to a single published study (7). The authors found more rapid loss of alveolar liquid in premature than in more mature animals whose fetal lung liquid contained surfactant. but fluid was displaced from alveolar to interstitial space rather than being cleared from the lung. The alveolar epithelial barrier also became freely permeable to macromolecules, a characteristic not found in the more mature animals. These findings are of interest because deposition of plasma protein in the airspace and lung edema are characteristics of surfactant deficient respiratory failure in infants (hyaline membrane disease) $(5,9)$ even though the above study (7) was limited to only $1 \mathrm{~h}$ of breathing and used a single, low volume ventilatory pattern.

This project was undertaken to expand our previous study.
We sought to measure and compare alveolar liquid absorption and rate of loss of three hydrophilic radiolabeled tracer solutes of different sizes in alveolar liquid during the start of breathing as has been done in 142-145-d gestation lambs (6) to determine if the mechanisms for absorption were the same. Further, we planned to see whether the amount of ventilation affected alveolar liquid absorption in premature animals.

\section{MATERIALS AND METHODS}

Pregnant ewes, 133-141 d gestation by timed breeding, were anesthetized with chloralose if the fetus was to be ventilated, or with pentabarbital and spinal xylocaine in the four fetuses $139 \mathrm{~d}$ or more which were to breathe spontaneously. The fetus was exteriorized from the uterus with the umbilical circulation intact. The trachea was cannulated and a polyethylene catheter was placed in the right carotid artery. Blood $\mathrm{pH}, \mathrm{PO}_{2}$ and $\mathrm{PCO}_{2}$ were measured on a Radiometer $\mathrm{ABL}$ automatic blood gas analyzer. A sample of alveolar liquids was aspirated through the trachea and a sample saved. Trace amounts, $50-100 \mu \mathrm{Ci}$, of [ [ $\left.{ }^{131} \mathrm{I}\right]$ albumin (molecular radius, $3.5 \mathrm{~nm}$ ) and [ $\left.{ }^{125} \mathrm{I}\right]$ cytochrome C, New England Nuclear, NEZ 151 [ ${ }^{125} \mathrm{I}$ ]radio-iodination system (molecular radius, $1.7 \mathrm{~nm}$ ), were instilled back into the lamb alveolar liquid and mixed by aspirating alveolar liquid back and forth every 10 min for half an hour. The alveolar liquid was then sampled to determine its volume from the dilution of these tracers by the method of Normand et al. (15).

Protocol. Lambs were then ventilated with an intact umbilical circulation. In four, spontaneous ventilation was induced by application of cold water to the snout and tactile stimulation as described by Egan et al. (6). Mechanical ventilation was initiated in the other 14 fetal lambs: six at low tidal volume and low frequency, $5.5 \pm 0.3 \mathrm{ml} / \mathrm{kg}$ at $20 \mathrm{breath} / \mathrm{min}$ and 0 end expiratory pressure; and eight animals at higher tidal volume, $10.8 \pm 0.5$ $\mathrm{ml} / \mathrm{kg}$ at 40 breath $/ \mathrm{min}$ at 0 end expiratory pressure. Ventilation was controlled with a Bourns infant ventilator and tidal volume corrected for compliance of respirator hosing. All ventilation was on $100 \% \mathrm{O}_{2}$. Inspiratory pressures ranged from $24-36 \mathrm{~cm} \mathrm{H}_{2} \mathrm{O}$ in low volume ventilation and 35-51 in high volume ventilation. Ventilator settings were selected to vary barotrauma to the lungs and not to promote effective gas exchange.

At three intervals, after 20,60 , and $120 \mathrm{~min}$ of ventilation, ventilation was stopped while the animal remained oxygenated by the umbilical circulation. The lung was degassed by aspiration and absorption of remaining alveolar oxygen and an aliquot of the remaining alveolar liquid obtained. The volume of liquid still in the alveoli was determined by addition of $\left[{ }^{57} \mathrm{Co}\right]$ cyanocobalamin (molecular radius, $0.6 \mathrm{~nm}$ ) to the alveolar liquid sample and re-instilling it into the alveoli for $5 \mathrm{~min}$ and obtaining another sample. Details of this technique are described below. 
After $120 \mathrm{~min}$, the umbilical cord was severed and ventilation continued for 2 more hours. The animals were sacrificed by closing the trachea and interrupting the asphyxial response by intravenous $\mathrm{KCl}$ as the blood pressure started to decline. The lungs were removed, drained of blood from major arteries and veins, blotted of blood, weighed, and dried at $80^{\circ} \mathrm{C}$ to a constant weight for $48 \mathrm{~h}$ to determine dry weight.

Measurement of alveolar liquid volume. When tracers are added to alveolar liquid in the lung they reach a steady concentration from convective mixing and diffusion so that smaller molecules equilibrate in the volume more readily than larger molecules. As can be seen in Figure $1,\left[{ }^{57} \mathrm{Co}\right]$ cyanocobalamin reaches a steady concentration within $6 \mathrm{~min}$ of instillation into alveolar liquid of a fetus.

To measure alveolar liquid volume after breathing a sample of the lung liquid aspirated after de-gassing, $S_{1}$, is counted; a sample of the instillate after addition of $10-20 \mu \mathrm{Ci}$ of $\left[{ }^{57} \mathrm{Co}\right]$ cyanocobalamin, $\mathrm{S}_{2}$; and a sample of alveolar liquid $5 \mathrm{~min}$ after re-instillation and mixing, $S_{3}$. The volume of the alveolar liquid can be calculated by a mass balance equation:

$$
\mathrm{V}_{\mathrm{ALV}} \mathrm{S}_{3}=\left(\mathrm{V}_{\mathrm{ALV}}-\mathrm{V}_{1}\right) \mathrm{S}_{1}+\mathrm{V}_{1} \mathrm{~S}_{2}
$$

where $\mathrm{S}$ is $\left[{ }^{57} \mathrm{Co}\right]$ cyanocobalamin in samples 1,2 , and 3 and $\mathrm{V}_{1}$ is the volume re-instilled and $\mathrm{V}_{\mathrm{ALV}}$ is the total liquid volume in the airspace. Rearranging:

$$
\mathrm{V}_{\mathrm{ALV}}=\mathrm{V}_{1} \times \frac{\left(\mathrm{S}_{2}-\mathrm{S}_{1}\right)}{\left(\mathrm{S}_{3}-\mathrm{S}_{1}\right)}
$$

There are two potential errors. First, $\left[{ }^{57} \mathrm{Co}\right]$ cyanocobalamin is permeable to the epithelium and can diffuse out at $1-2 \% / \mathrm{min}$ which would tend to underestimate $\mathrm{S}_{3}$. If mixing of $\left[{ }^{57} \mathrm{Co}\right]$ cyanocobalamin throughout the remaining liquid is less efficient than shown in Figure $1, \mathrm{~S}_{3}$ will be artificially high. These two potential errors are in the opposite direction and both would give a maximum error of $5-10 \%$ of the real volume over 5 min of equilibration. Often at $2 \mathrm{~h}$ no alveolar liquid could be sampled.

Tracer concentration measurements. At each sampling of lung liquid, a $1.0-\mathrm{ml}$ aliquot was removed and counted on a gamma scintillation counter. All samples were counted in triplicate with simultaneous standards. Individual isotope counts were separated by a Nuclear Chicago multichannel analyser and corrected for spill by an inverted matrix and for isotope decay.

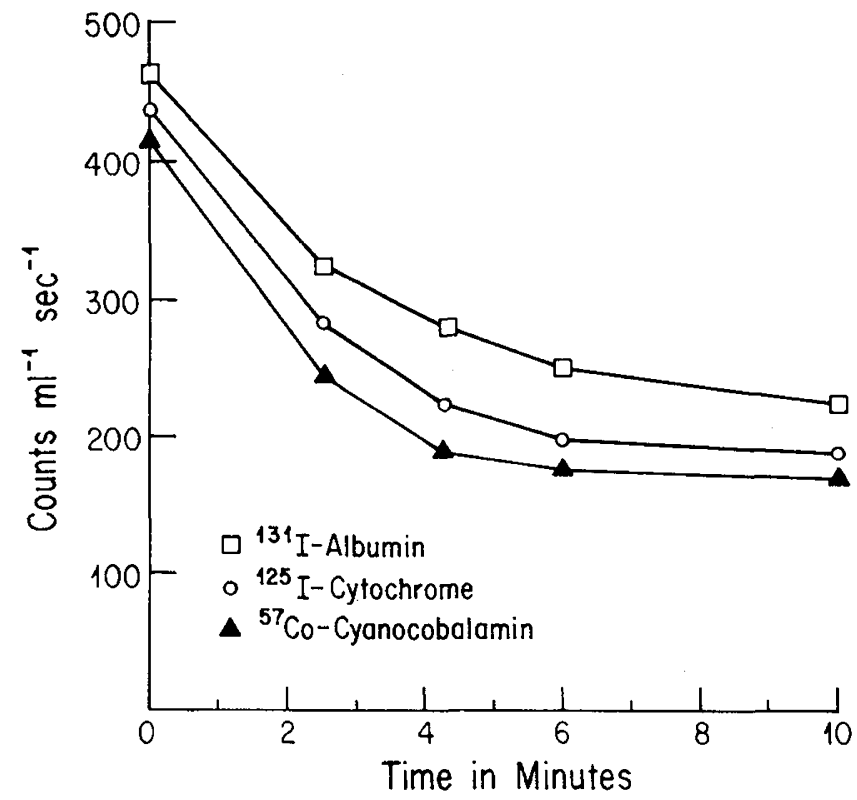

Fig. 1. Time course for instilled tracer solutes to equilibrate in fetal lung liquid by diffusion and mixing. $\left[{ }^{57} \mathrm{Co}\right.$ cyanocobalamin concentration decrease is $93 \%$ by $4 \mathrm{~min}$ and $98 \%$ by $6 \mathrm{~min},\left[{ }^{125} \mathrm{I}\right]$ cytochrome $\mathrm{C}$ is $94 \%$ by $\left.6 \mathrm{~min},{ }^{[13} \mathrm{I}\right]$ albumin is $82 \%$ by $6 \mathrm{~min}$.
Alveolar phospholipid measurement. All fetal lung liquid samples were tested for phospholipid at the time of experiment by the bubble stability test, and all were negative at a 1:1 dilution. Fetal lung liquid and alveolar liquid removed after $20 \mathrm{~min}$ of ventilation were assayed for phospholipid concentration by the micro-determination method of phosphorous (4). Total alveolar liquid phospholipid content was calculated from concentration and lung liquid volume measurements.

\section{RESULTS}

The absorption from the alveolar space of lung liquid in all three groups was extremely rapid, especially in the first $20 \mathrm{~min}$ of spontaneous breathing or ventilation. In Figure 2, the alveolar liquid volume of each animal in the three groups is plotted as measured at 20,60 , and $120 \mathrm{~min}$ after ventilation. In every animal, well over half, and often $75 \%$ or more of the alveolar liquid disappears from the alveoli within $20 \mathrm{~min}$. The mean rate of absorption measured in 142-145 d gestation spontaneously ventilating lambs from Egan et al. (6) is plotted for comparison with the spontaneously breathing lambs from this series. Generally, after the initial, very rapid, decrease in volume over the first $20 \mathrm{~min}$, the alveolar liquid absorption slows in all spontaneously breathing and low ventilation groups, but remains rapid in the high ventilation group. One animal in the high ventilation group developed what appears to be the hemorrhagic pulmonary edema syndrome sometimes seen in infants with severe lung disease. This animal showed a substantial increase in alveolar liquid between 20 and $60 \mathrm{~min}$ of ventilation.

Figure 3 shows alveolar liquid volume changes over time together with the concentration of the three tracer solutes in the alveolar liquid. Decreasing concentration of a tracer indicates it is leaving the airspace more rapidly than water is being absorbed, increasing tracer concentration indicates a slower loss from the alveolar space than water and constant concentration means tracer and water loss is equal. In spontaneously breathing animals from $0-20 \mathrm{~min}$, there is a great decrease in alveolar liquid volume, but no significant change in $\left[{ }^{131} \mathrm{I}\right]$ albumin or $\left[{ }^{125} \mathrm{I}\right]$ cytochrome $\mathrm{C}$ concentration in the alveolar liquid, indicating that liquid and its solutes are being absorbed across the bloodgas barrier as a bulk phase. From 20-60 min a very different picture emerges. The decrease of lung liquid volume approximates the increase in concentration of both [ $\left.{ }^{131} \mathrm{I}\right]$ albumin and $\left.{ }^{125} \mathrm{I}\right]$ cytochrome $\mathrm{C}$ on the $\log$ scale of the abscissa, indicating that tracer increase in concentration can result totally from loss of liquid volume if the tracers are now restricted to the alveolar space. $\left[{ }^{57} \mathrm{Co}\right]$ Cyanocobalamin, the smallest tracer, decreases in concentration indicating diffusional loss from the alveolar space for this tracer.

The low ventilation and high ventilation groups in Figure 3 have the same pattern as the spontaneously breathing animals for the first $20 \mathrm{~min}$. There is a large volume absorbed but tracer concentration in alveolar liquid is unchanged. From 20-60 min, low ventilation animals show no statistically significant change in $\left[{ }^{131} \mathrm{I}\right]$ albumin or $\left[{ }^{125} \mathrm{I}\right]$ cytochrome $\mathrm{C}$ concentrations, indicating a continuation of bulk place absorption. High ventilation animals show insignificant changes in [ $\left.{ }^{131} \mathrm{I}\right]$ albumin from $20-60 \mathrm{~min}$, but decreasing concentration of both $\left[{ }^{125} \mathrm{I}\right]$ cytochrome $\mathrm{C}$ and $\left[{ }^{57} \mathrm{Co}\right]$ cyanocobalamin. The decreasing concentration of the smaller tracers indicates diffusional efflux from the alveolar space in addition to bulk absorption. All mechanically ventilated animals absorbed water and [ $\left.{ }^{131} \mathrm{I}\right]$ albumin as a bulk phase during the entire first hour and high volume ventilated animals showed diffusion efflux of $\left[{ }^{125} \mathrm{I}\right]$ cytochrome $\mathrm{C}$ in addition.

In Table 1, the pooled data for blood gases for the three groups is detailed. Spontaneously breathing animals slowly recovered from initial respiratory insufficiency and hypoxemia. Low ventilation animals and high ventilation animals showed persistent hypoxemia and progressive hypercapnea during the $4 \mathrm{~h}$.

Table 2 details phospholipid and total lung water content for 


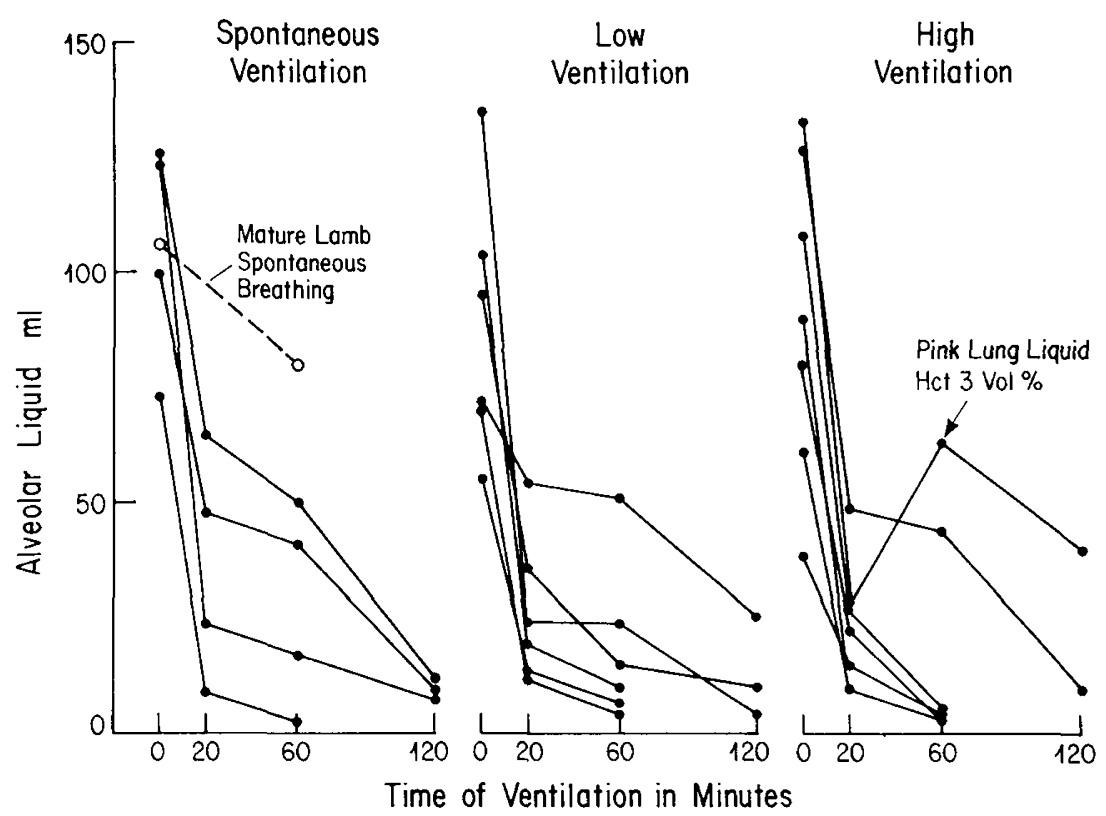

Fig. 2. Measurements of alveolar liquid volumes before breathing and after 20,60 , and 120 min of breathing in 18 premature lambs. Variation in absorption rate in four mature lambs from (6) were less than $10 \%$.

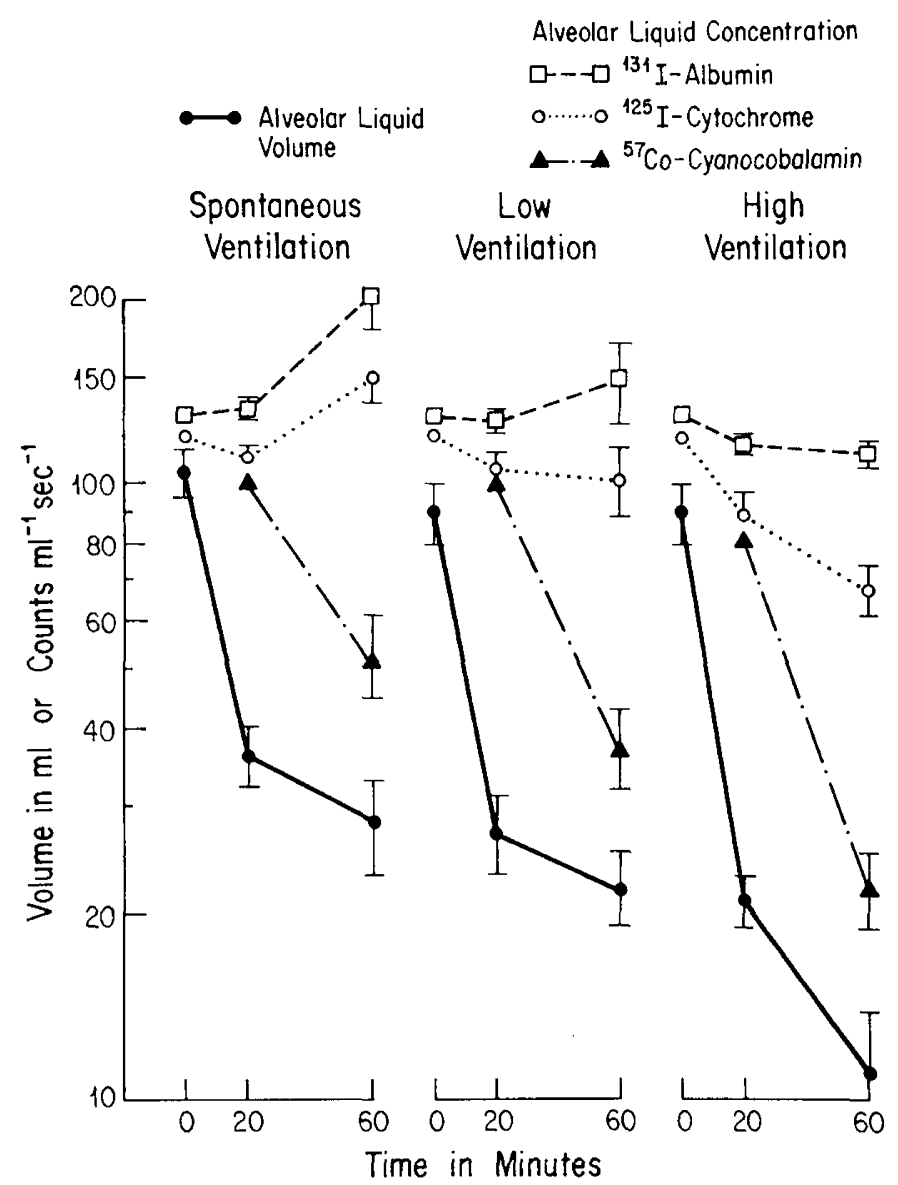

Fig. 3. Lung liquid absorption and alveolar liquid tracer solute concentration changes in three groups of breathing premature lambs. Values are mean $\pm \mathrm{SE}$.

the three groups. The older, spontaneously breathing animals released three times the amount of phospholipid into the alveolar space as did the younger, mechanically ventilated animals. After $4 \mathrm{~h}$ of breathing, the spontaneously breathing animals had a significantly lower wet weight:dry weight ratio of the lungs, although it is still above normal values $\leq 5.0$.

\section{DISCUSSION}

Alveolar liquid absorption rate and the solute permeability of the epithelial layer through which it is absorbed appear to depend on the maturity of the fetus, both in this study and in previous ones $(6,7)$. The mature fetal lung, biologically adapted for initiation of breathing, has already secreted surfactant into the alveolar space (13). Classification of our animals as premature is based on both gestational age and the absence of detectable lung surfactant in alveolar liquid before the onset of breathing. In the initial study of alveolar liquid absorption, lambs were in the last week of gestation, 142-145 d, and it is probable that surfactant was present in the alveolar space before ventilation, but no measurement was made (8). In the study of goats, surfactant was present in the alveolar space in the group judged "mature," despite their gestational age assignment being only $138 \pm 2 \mathrm{~d}(7)$. The gestational ages for the goats were estimated from $x$-rays, not timed breedings, and those with alveolar surfactant may have been older than estimated.

The absorption of lung liquid in all of these premature lambs during the first $20 \mathrm{~min}$ was by bulk flow; water and all tracer solutes were absorbed from the alveolar space at the same rate. Lung liquid absorption in 142-145-d gestation lambs was not by bulk flow; water and solutes were absorbed at different rates and tracer macromolecular solutes were not absorbed at all (6). Bulk flow absorption requires large passages across the alveolar epithelium which have low hydraulic conductivity and a large enough size $(\gg 3.5 \mathrm{~nm})$ so that there is no sieving of $\left[{ }^{131} \mathrm{I}\right]$ albumin. Bulk flow absorption occurred in all groups of premature lambs so that ventilation itself, not the method or degree of ventilation, induced the phenomenon. Macromolecular permeability of lung epithelium at the initiation of breathing was found in premature ventilated goats without detectable surfactant, but not in ventilated goats with detectable surfactant in fetal lung liquid (7) nor in 142-145-d gestation spontaneously breathing lambs (6). It appears that ventilation of surfactant-deficient lungs for only a few minutes creates a number of pathways across the alveolar epithelium which permits bulk absorption of lung liquid. Current studies with pre-ventilation instillation of exogenous surfactant in premature animals will define whether surfactant or lung immaturity is the important factor which distinguishes premature from full-term animals.

Superficially, it would appear advantageous for newborn animals to rapidly displace liquid from the airspace into the inter- 
Table 1. Ventilation and blood gas in premature lambs ventilating $100 \%$ oxygen (mean \pm SE)

\begin{tabular}{|c|c|c|c|c|c|c|c|c|c|c|c|c|}
\hline & \multirow[b]{3}{*}{$n$} & \multirow{3}{*}{$\begin{array}{c}\mathrm{V}_{\mathrm{T}} / \mathrm{f} \\
\left(\mathrm{ml} \cdot \mathrm{kg}^{-1} / \mathrm{min}\right)\end{array}$} & \multirow{3}{*}{$\begin{array}{l}\mathrm{Wt} \\
(\mathrm{kg})\end{array}$} & \multirow{3}{*}{$\begin{array}{l}\text { Gesta- } \\
\text { tional } \\
\text { age } \\
\text { (d) }\end{array}$} & \multicolumn{8}{|c|}{ Time since beginning breathing } \\
\hline & & & & & \multicolumn{2}{|c|}{$20 \mathrm{~min}$} & \multicolumn{2}{|c|}{$60 \mathrm{~min}$} & \multicolumn{2}{|c|}{$120 \mathrm{~min}$} & \multicolumn{2}{|c|}{$240 \mathrm{~min}$} \\
\hline & & & & & $\mathrm{PaO}_{2}$ & $\mathrm{PaCO}_{2}$ & $\mathrm{PaO}_{2}$ & $\mathrm{PaCO}_{2}$ & $\mathrm{PaO}_{2}$ & $\mathrm{PaCO}_{2}$ & $\mathrm{PaO}_{2}$ & $\mathrm{PaCO}_{2}$ \\
\hline $\begin{array}{l}\text { Low ventila- } \\
\text { tion }\end{array}$ & 6 & $5.5 \pm 0.3 / 20$ & $4.7 \pm 0.7$ & $137 \pm 2$ & $27 \pm 9^{*}$ & $54 \pm 5$ & $44 \pm 11$ & $58 \pm 9$ & $47 \pm 11$ & $59 \pm 7$ & $42 \pm 14$ & $108 \pm 14$ \\
\hline
\end{tabular}

* Mean differed from both of the other groups $(P<0.05)$.

Table 2. Alveolar surfactant release and lung water in ventilated premature lambs (mean $\pm S E$ )

\begin{tabular}{lccc}
\hline & \multicolumn{2}{c}{$\begin{array}{c}\text { Total alveolar phospholipid } \\
\text { (u mol) }\end{array}$} & \\
\cline { 2 - 3 } \multicolumn{1}{c}{ Groups } & Fetal & $\begin{array}{c}\text { After 20 min } \\
\text { breathing }\end{array}$ & $\begin{array}{c}\text { Wet:dry lung } \\
\text { weight }\end{array}$ \\
\hline Spontaneous breathing & $3.4 \pm 0.4$ & $302 \pm 82^{*}$ & $5.7 \pm 0.2^{*}$ \\
Low ventilation & $2.9 \pm 0.3$ & $84 \pm 12$ & $6.3 \pm 0.3$ \\
High ventilation & $2.7 \pm 0.2$ & $99 \pm 43$ & $6.3 \pm 0.2$ \\
\hline
\end{tabular}

* Mean differs from other groups $(P<0.05)$.

stitium of the lung to promote more effective movement of gas in and out of the exchange areas. All of these animals cleared liquid from their alveoli much more rapidly than do $142-145-d$ gestation sheep, yet even the spontaneously ventilating animals with significant amounts of surfactant release were in respiratory failure until $4 \mathrm{~h}$ of breathing. Further, the more immature ventilated groups had a large excess of interstitial lung water, which was still present at $4 \mathrm{~h}$. The amount of edema was similar to that seen in lungs of infants who die of hyaline membrane disease $(5,12)$. This is consistent with the measurements of Humphreys et al. (10) that lung lymph flow increases less in immature ventilated lambs than in more mature lambs. It appears that rapid clearance of fetal liquid from the alveoli in immature lambs does not mean that the total clearance from the lung is normal and that an excess of liquid, which calculates to $10-15 \mathrm{ml} / \mathrm{kg}$ body weight or $50 \%+$ of the fetal alveolar liquid, remains in the lung interstitium after $4 \mathrm{~h}$. This data suggest that interstitial edema in respiratory failure of prematures is an early feature and related to failure of clearance of alveolar liquid from the lung, as well as a late event related to excess pulmonary blood flow from a patent ductus arteriosus.

The spontaneously breathing group had increasing alveolar liquid concentration of $\left[{ }^{131} \mathrm{I}\right]$ albumin and $\left[{ }^{125} \mathrm{I}\right]$ cytochrome $\mathrm{C}$ after $20 \mathrm{~min}$. Back diffusion from previously absorbed tracer is a possible explanation, but unlikely, because the mechanically ventilated animals had similar early bulk liquid absorption but no evidence of a later increase in alveolar liquid concentration in the tracers. The alveolar epithelium of the spontaneously breathing animals no longer allow efflux of $\left[{ }^{131} \mathrm{I}\right]$ albumin and $\left[{ }^{125} I\right]$ cytochrome $C$ from the alveolar space, although total volume and $\left[{ }^{57} \mathrm{Co}\right]$ cyanocobalamin are absorbed and at different rates. This epithelial sieving of the solutes after $20 \mathrm{~min}$ while alveolar liquid absorption continues fits the pattern observed in 142-145-d gestation lambs (6).

Lung overdistention in adult animals induces significant protein permeability of the alveolar epithelium, specifically if the overdistention is limited to only a fraction of the airspace (8). Ventilation of surfactant-deficient premature lungs produces aeration of only a fraction of the airspaces and much of the lung remains unaerated even at high static pressures $(19,20)$. Hyperinflation of some of the areas of the lung that are aerated is observed in anatomic studies in human infants (12). In ventilated, surfactant-deficient rabbits, bronchiolar epithelial desqualmation and necrosis occurs (14). Hyperexpanded alveoli or de- nuded bronchial walls may be the site for bulk flow absorption. Because bulk flow appeared to stop after $20 \mathrm{~min}$ in spontaneously ventilated animals who secreted significant surfactant into the alveolar space, but did not cease in the younger ventilated animals, surfactant secretion appears to affect post-ventilation changes in the mechanism of postnatal alveolar liquid absorption. Exogenous surfactant instillation is reported by Jobe et al. (11) to decrease protein flux into the alveoli in ventilated premature lambs.

Studies on initiation of pulmonary ventilation in term newborn animals and man has focused primarily on ventilation, respiratory gas exchange, and pulmonary blood flow. Premature animal and human studies have emphasized the same functions and particularly the role of lung surfactants in lung ventilatory function. Knowledge of the rate and mechanisms of absorption of the fetal lung liquid, a unique requirement of the newly born, and the significance of abnormalities in the clearance for neonatal lung function in premature or full-term newborn animals and humans is extremely limited. These premature lambs show very rapid clearance of liquid volume from the airspace without sieving solutes and persistence of excess liquid in the lung interstitium. The contribution of these phenomena to their respiratory failure and any lung architectural injury and chronic lung changes has not been defined. Perinatal lung liquid fluxes impose an additional factor on the management of respiratory failure in newborns, a factor whose importance remains unspecified.

\section{REFERENCES AND NOTES}

1. Adams, F. H. Yanagisawa, M., Kuzela, D., Martinek, H.: The disappearance of fetal lung liquid following birth. J. Pediatr., 78: 837 (1971).

2. Bland, R. D., McMillan, D. D., Bressack, M. A., and Dong, L.: Clearance of liquid from lungs of newborn rabbits. J. Appl. Physiol.: Respirat. Environ., Exer. Physiol., 49: 171 (1980).

3. Brown, M. J., Olver, R. E., Ramsden, C. A.. Strang, L. B., and Walters, D. V.: Effects of adrenaline infusion and spontaneous labor on lung liquid secretion and absorption in the fetal lamb. J. Physiol. (London), 313: 13P (1980).

4. Chen, P. S.. Toribarra, T. Y., and Huber, W.: Microdetermination of phosphorus. Anal. Chem.. 28: 1756 (1956).

5. DeSa. P. J.: Pulmonary fluid content in infants with respiratory distress. $J$ Pathol., 97: 469 (1969).

6. Egan, E. A., Olver, R. E., and Strang. L. B.: Changes in non-electrolyte permeability of alveoli and the absorption of lung liquid at the start of breathing in the lamb. J. Physiol. (London), 244: 161 (1975).

7. Egan, E. A., Nelson. R. M., and Beale, E. F.: Lung solute permeability and lung liquid absorption in premature ventilated fetal goats. Pediatr. Res., 14: 314 (1980).

8. Egan, E. A.: Lung inflation, lung solute permeability, and alveolar edema. J. Appl. Physiol: Respirat. Environ.. Exer. Physiol.. 53: 121 (1982).

9. Gitlin, D. and Craig, J. M.: The nature of the hyaline membrane in asphyxia of the newborn. Pediatrics, 17: 64 (1965).

10. Humphreys, P. W.. Normand, I. C. S., Reynolds, E. O. R., and Strang, L. B.: Pulmonary lymph-flow and uptake of liquid from the lungs of the lamb at the start of breathing. J. Physiol. (London), 193: 1 (1967).

11. Jobe, A. H., Ikegami, M., Jacobs, H. C., Jones, S. J., and Conaway, D.: Alveolar protein permeability and the affect of natural surfactant on protein permeability in premature lambs. J. Appl. Physiol: Respirat. Environ. Exer. Physiol. (abstract), 5.5: 169 (1983).

12. Lauweryns, J. M.: Hyaline Membrane Disease: a pathological study of 55 infants. Arch. Dis. Child., 40: 618 (1965).

13. Mescher, E. J., Platzker, A. C. G., Ballard, P. L.. Kitterman, J. A., Clements, J. A., and Tooley, W. H.: Ontogeny of tracheal fluid pulmonary surfactant and plasma corticoids in the fetal lamb. J. Appl. Physiol., 39: 1017 (1975).

14. Nilsson. R.. Grossmann, G., and Robertson, B.: Lung Surfactant and the 
pathogenesis of neonatal bronchiolar lesions induced by artificial ventilation. Pediatr. Res.. 12: 249 (1978)

15. Normand. I. C. A., Olver, R. E.. Reynold, E. O. R.. Strang, L. B., and Welch, K.: Permeability of lung capillaries and alveoli to non-electrolytes in the foetal lamb. J. Physiol. (London), 219: 303 (1975).

16. Olver. R. E., Ramsden. C. A.. and Strang, L. B.: Adrenaline-induced changes in net lung liquid volume flow across the pulmonary epithelium of the fetal lamb: cvidence for active sodium transport. J. Physiol. (London), 319: 38P (1981).

17. Olver, R. E.: Of labor and the lungs. Arch. Dis. Child.. 56: 659 (1981).

18. Orzalesi, M. M., Motoyama, E. K., Jacobson, H. N., Kikkawa, Y., Reynolds, E. O.R., and Cook, C. D.: The development of the lungs of lambs. Pediatrics, 3.5: 373 (1965).
19. Reynolds, E. O. R., Robertson, N. R. C., and Wigglesworth, J. S.: Hyaline membrane diseasc, respiratory distress and surfactant deficiency. Pediatrics, 42: $758(1980)$.

20. Strang. L. B.: Neonatal Respiration. pp. 181-218 (Blackwell, London, 1977). 21. Phospholipid determinations were made through the generous assistance of Dr. Donald Shapiro, Univ, of Rochester School of Medicine and Dentistry.

22. Technical assistance was provided by Mr. Bruce McIntyre and assistance in manuscript preparation by Ms. Dorothy Giallella.

23. Address for correspondence and reprints is: Edmund A. Egan, Children's Hospital. 219 Bryant St.. Buffalo. NY 14222.

24. This work was supported by NIH-HBLI Grant 22552

25. Received for publication June 6, 1983.

26. Accepted for publication September 22, 1983.
0031-3998/84/1806-0570\$02.00/0

PEDIATRIC RESEARCH

Copyright (C) 1984 International Pediatric Research Foundation, Inc. Letter to the Editor

JOAN L. CADDELL ${ }^{(28)}$

Human Genetics Branch, National Institute of Child Health and Ituman Developinent. National Institutes of Health, Bethesda. Marvland USA

Dr. Marilyn Erickson and four St. Louis coinvestigators (10, 11) recently reported a study of magnesium and other minerals in selected tissues from infants dying of sudden infant death syndrome (SIDS) and from controls dying of known cause. They found that the SIDS liver and rib specimens showed significantly more lead than the non-SID counterparts. They concluded that their study provided no support for a hypothesis $(2,5)$ that magnesium deficiency is a major factor in the pathogenesis of SIDS, "because there were no significant differences in lung, kidney, or rib magnesium concentrations between SIDS and non-SIDS groups. Indeed, the liver magnesium was higher in the SIDS group $(P<0.0001) \ldots "(11)$. This is a response to that statement, and a comment on the heavier lead burden in the SIDS tissues.

The diagnosis of magnesium deficiency in early life is difficult to establish $(4,13)$. Many investigators $(4,6,12,13,18)$ have shown that the concentration of magnesium in soft tissues is well maintained in magnesium deficiency. In view of this, Günther (13) suggested that the metabolic effects of severe magnesium deficiency may be caused by increased permeability of cell membranes and by alterations of intracellular electrolytes other than magnesium-increased calcium and sodium, and decreased potassium $(4,13,16)$. These effects are often greater in heart and skeletal muscle than in liver and kidney $(12,13)$. In the St. Louis study (11), selected tissues were analyzed for calcium and magnesium, but not for sodium and potassium. The concentrations of calcium and magnesium from SIDS versus non-SIDS infants, showed insignificant changes in the directions found in magnesium deficiency: calcium was increased in lung and liver, and magnesium was decreased in lung and kidney. The increased liver magnesium will be considered separately in this letter.

Increased renal calcium was reported in magnesium deficient adult rats (16). Erickson et al. (11) found no change in the calcium concentration of the renal cortex; the medulla was not analyzed. The sites of deposition of calcium phosphate calculi in magnesium deficiency are the thick ascending limb and the thin limb of Henle (21), located chiefly in the medulla (1). Microliths grow slowly by accretion (21); perhaps the young infants would not have had time to accumulate a significant degree of calcium if they were deficient in magnesium.

The concentration of magnesium in the ribs of SIDS infants was essentially the same as control values, showing only a slight decrease (11). The authors cited a report that identified bone as the best diagnostic tissue to evaluate dietary or acquired magne-
Vol. 18 , No. 6,1984 Printed in U.S.A. sium deficiency in rats that were normal at the onset of the study. In this study, weanling rats fed a magnesium deficient diet for $1 \mathrm{wk}$ showed little difference in soft tissue magnesium but a $60 \%$ reduction in magnesium in rib or femur, compared with control values (4). Retrospective studies of infants dying of SIDS showed that the infants had been physiologically handicapped from before birth (25), suggesting the need to examine an animal model for congenital magnesium deficiency. A study in an animal model at the NICHD (7) has shown that, unlike the bone of rat pups with acquired dietary magnesium deficiency $(4,6)$, the bones of rat pups borne and suckled by dams fed two extremes of dietary magnesium during pregnancy and lactation showed little change in magnesium concentration. A difference of $11 \%$ bone magnesium was found in 10-d-old pups from dams fed 5 versus $150 \mathrm{mg}$ of magnesium/100 g diet. In another study (8), a $5 \%$ difference was found in bone magnesium of pups from dams fed 15 versus $60 \mathrm{mg}$. Despite these relatively small changes, the pups showed metabolic abnormalities comparable to magnesium deficiency. It is therefore believed that the change in magnesium concentration in bone of infants with congenital magnesium deficiency would be relatively small and difficult to detect in a clinical situation (7).

The St. Louis group reported a significant (10.8\%) increase in the magnesium concentration of liver in the SIDS infants (11) compared with controls. Lapin and his associates (15) also studied liver in SIDS and non-SIDS controls ( $5 \mathrm{~d}$ to $13 \mathrm{yr}$ in age) but found a decrease, although the difference was not significant. Changes in the concentration of liver magnesium with maturity and postnatal age as reported by Widdowson and McCance (26) could explain all of these findings. In $\mathrm{mEq} / \mathrm{kg}$ of fat-free tissue, liver magnesium was 14.7 in the 20 -wk fetus. It decreased to 10.4 in the full term newborn and then gradually increased, reaching 11.8 in the 4-7-mo-old baby and 15.2 in the adult. Liver magnesium is also increased in the 2-yr-old horse compared with the yearling (22). In the St. Louis report, the gestational ages were not stated. Unless matched for maturity, the agematched St. Louis SIDS infants might well show higher values, because prematurity is over-represented in SIDS. In contrast, the chronologic age difference in Lapin's study could account for higher values in the controls because they were older.

Regardless of age and maturity, liver is an inappropriate tissue to assess the magnesium status of a mammal (3). The magnesium concentration of liver does not decrease appreciably, if at all, in magnesium deficiency $(5,6,16,23)$ and may not increase in magnesium excess (9). In a controlled study, tissues from chronic uremic patients showed no change in liver magnesium whereas there was an increased magnesium concentration in plasma, erythrocytes, myocardium, lung, skin, and cortical bone (9).

The liver behaves differently from other organs in magnesium deficiency (18). In one study, the magnesium content of the entire organ increased $18 \%$ during the first $15 \mathrm{~d}$ of dietary deficiency, paralleling an increase in non-collagen nitrogen, and then gradually decreased. The magnesium concentration of the 
liver of acutely deficient weanling animals was slightly higher than the control value in two studies $(4,19)$. In one, the magnesium-deficient rats showed an $11 \%$ increase (NS) in the concentration of liver magnesium compared with control values after all animals were fasted for $20 \mathrm{hs}$ (19). In a report of the cellular composition of rat liver in magnesium deficiency, the magnesium concentration of the nuclear fraction increased; the concentration in the heavy mitochondria decreased (12); thus, the liver in the magnesium-deficient rat may initially accumulate and redistribute magnesium. This conceivably could be related to the known high requirements for this mineral in multiple aspects of liver metabolism $(12,23)$. Schwartz and associates (23), commenting on the lack of change of liver magnesium in rats while the total carcass magnesium varied markedly with magnesium intake, suggested that magnesium was preferentially preserved in tissue of active protein synthesis during dietary magnesium deficiency. The fact that liver magnesium may increase in an early stage of magnesium deficiency, but not at a time of magnesium excess, raises the possibility of magnesium deficiency in SIDS infants with increased liver magnesium.

The St. Louis group found an increased lead burden in SIDS infants (10); no mention was made of socioeconomic or environmental factors associated with increased lead exposure. It is known that deficiency in several essential nutrients including four essential minerals increase the lead deposition in experimental animals: calcium, zinc, iron (19), and magnesium (8). No differences were found in zinc or calcium levels between SIDS and non-SIDS infants. Iron was not studied by the St. Louis investigators $(10,11)$. Continuing with the above reasoning concerning magnesium, if the SIDS infants showed more magnesium deficiency than the non-SIDS infants, this might explain their increased lead burden, as suggested by studies in animal models. The St. Louis group (11) cited a study that the addition of magnesium to a commercial stock diet already providing adequate magnesium reduced lead toxicity in the rat by increasing urinary excretion of lead mobilized from bone (24). Similarly, supplemental magnesium reduced the toxicity of lead in embryos of the amphibian Xenopus laevis (20). Other investigators have reported increased tissue lead concentration in magnesium-deficient rats (14). More pertinent here is a recent study (8) revealing that moderate magnesium deficiency in rat dams (mild enough to permit $100 \%$ survival of offspring) resulted in increased lead burden in dams and pups. The pups showed changes in tissue magnesium and lead as follows: a $5 \%$ decrease in bone magnesium and significantly higher levels of lead in erythrocytes, liver, and tibia. The poor dietary intake of magnesium, together with the high metabolic demand for this mineral during pregnancy, resulted in conditioned magnesium deficiency in the dams and congenital magnesium deficiency in the pups (8). Lead, which is readily transferred across the placental barrier to the fetus (17), showed a higher concentration in bone of offspring than that of dams (NS) (8).

It appears to this reader that the conclusions reached by the St. Louis group are not justified on the basis of what is known about the concentration of magnesium, lead, and related cations in soft tissue and bone in young mammals with congenital and acquired or dietary magnesium deficiency. A maternal dietary history, knowledge of the maturity and the diet of the infant, and information concerning the toxic minerals in the environment are needed to properly interpret the data.

\section{REFERENCES.AND NOTES}

1. Bloom, W. and Fawcett. D. W.: The urinary system. In: A Textbook of Histology. 9th edition, p. 652. (Saunders, Philadelphia, 1968).

2. Caddell, J. L.: Magnesium deprivation in sudden unexpected infant death. Lancet. 2: 258 (1972).

3. Caddell, J. L.: Hepatic trace elements in the sudden infant death syndrome. J. Pediatr.. 90: 1039 (1977)

4. Caddell, J. L. and Scheppner, R.: The postmortem diagnosis of magnesium deficiency: studies in an animal model for the human infant. J. Forensic Sci., 23: 335 (1978).

5. Caddell, J. L.: Exploring the magnesium-deficient weanling rat as an animal model for the sudden infant death syndrome: physical, biochemical, electrocardiographic, and gross pathologic changes. Pediatr. Res., I2: 1157 (1978).

6. Caddell, J. L.. Calhoun. N. R., Howard, M. P.. Patterson, K. Y. and Smith, J $\mathrm{C}$. Jr.: Parenteral magnesium load testing with ${ }^{28} \mathrm{Mg}$ in weanling and young adult rats. J. Nutr. 111: 1033 (1981)

7. Caddell, J. L.: The effect of maternal dietary magnesium and postnatal age on the concentration of magnesium and calcium in bone of neonatal rat pups. Pediatr. Res. (abstract), 17: 184A (1983).

8. Cerklewski, F. L.: Influence of maternal magnesium deficiency on tissue lead content of rats. J. Nutr., /13: 1443 (1983).

9. Contiguglia, S. R., Alfrey, A. C., Miller, N., and Butkus, D.: Total-body magnesium excess in chronic renal failure. Lancet, $1: 1300$ (1972).

10. Erickson, M. M.. Poklis, A., Gantner, G. E., Dickinson, A. W., and Hillman, L. S.: Tissue mineral levels in victims of sudden infant death syndrome. 1 . Toxic metals-lead and cadmium. Pediatr. Res., 17: 779 (1983)

11. Erickson, M. M., Poklis, A., Gantner, G. E., Dickinson, A. W., and Hillman, L. S.: Tissue mineral levels in victims of sudden infant death syndrome. II. Essential minerals: copper, zinc, calcium, and magnesium. Pediatr. Res., 17 784 (1983).

12. George, G. A. and Heaton, F. W.: Changes in cellular composition during magnesium deficiency. Biochem. J., 152: 609 (1975).

13. Günther, T.: Biochemistry and pathobiochemistry of magnesium. Artery, 9: $167(1981)$.

14. Krall, A. R. and McLean. M. S.. Jr.: Effects of varying dietary magnesium and phosphate on tissue lead content of lead-fed rats. In: M. Cantin and M. S. Seelig: Magnesium in Health and Disease. p. 955 (Spectrum, New York. 1980)

15. Lapin. C. A., Morrow, IH, G., Chvapil, M. Belke, D. P., and Fisher, R. S.: Hepatic trace elements in the sudden infant death syndrome. J. Pediatr., 89 . 607 (1976).

16. Macintyre, I. and Davidsson, D.: The production of secondary potassium depletion, sodium retention, nephrocalcinosis and hypercalcaemia by magnesium deficiency. Biochem. J., 70: 456 (1958).

17. Mahaffey, K. R.: Nutritional factors in lead poisoning. Nutrition Rev., 39: 353 (1981).

18. Martindale, L. and Heaton, F. W.: Magnesium deficiency in the adult rat Biochem. J., 92: 119 (1964).

19. McNeill, D. A., Herbein, J. H., and Ritchey, S. J.: Hepatic gluconeogenic enzymes. plasma insulin and glucagon response to magnesium deficiency and fasting. J. Nutr., 112: 736 (1982).

20. Miller, J. C. and Landesman, R.: Reduction of heavy metal toxicity to Xenopus enzymes by magnesium ions. Bull. Environm. Contam. Toxicol., 20: 93 (1978).

21. Oliver, J. Mac Dowell, M. Whang, R., and Welt, L. G.: The renal lesions of electrolyte imbalance. IV. The intranephronic calculosis of experimental magnesium depletion. J. Exper. Med., 124: 263 (1966).

22. Schryver, H. F., Hintz, H. F., Lowe, J. E., Hintz. R. L., Harper, R. B., and Reid, J. T.: Mineral composition of the whole body, liver, and bone of young horses. J. Nutr., I04: 126 (1974).

23. Schwartz. R., Wang. F. L., and Woodcock, N. A.: Effect of varying dietary protein-magnesium ratios on nitrogen utilization and magnesium retention in growing rats. J. Nutr., 97: 185 (1969).

24. Singh, N. P., Thind, I. S., Vitale, L. F., and Pawlow, M.: Intake of magnesium and toxicity of lead. An experimental model. Arch. Environ. Health, 34: 168 (1979).

25. Valdès-Dapnea, M. A.: Sudden infant death syndrome: a review of the medical literature 1974-1979. Pediatrics, 66: 597 (1980).

26. Widdowson. E. M. and McCance, R. A.: The metabolism of calcium, phosphorus, magnesium and strontium. Pediatr. Clin. N. Am., 12: 595 (1965).

27. Guest Researcher privileges provided through the kindness of James B. Sidbury, Jr., M.D., Intramural Program, Human Genetics. Branch, The National Institute of Child Health and Human Development, The National Institutes of Health, have made it possible to continue this work, and are most gratefully acknowledged.

28. Requests for reprints should be addressed to: Joan L. Caddell, M.D., HGB, NICHD, Building 10.8 D-52, National Institutes of Health, Bethesda, MD 20205. USA.

\section{Response}

MARILYN M. ERICKSON AND LAURA S. HILLMAN

Department of Pediatrics, Washington University School of Medicine, St. Louis, Missouri USA

The primary purpose of our study was to see if the concentration of cadmium and lead $(\mathrm{Pb})$, toxic metals, would be elevated in the tissues of victims of sudden infant death syndrome (SIDS) (6). The renal cortex is the major storage site for cadmium (8) and bone is the major storage site for lead (9). The concentration of these metals in the liver is a reflection of recent exposure by ingestion. We elected to measure these metals in lung tissue to see if the lung levels would reflect recent exposure by inhalation. 
Because of numerous reports of studies showing interactions of cadmium and lead with the essential minerals such as copper, zinc, calcium, and magnesium, we felt it necessary to measure these minerals also (7). We were not aware of any reports of studies showing interactions of cadmium and/or lead with sodium or potassium and, therefore, did not measure these ions. At the time these measurements were made, it was not possible for us to reliably assess the iron status of these infants although we were aware that an iron deficiency can effect increased lead absorption. Since then, we have been assessing iron status in SIDS victims and preliminary results show no evidence of an iron deficiency in these infants.

It was not our intention to use liver tissue to assess magnesium deficiency. The hypothesis and animal model put forth by Dr. Caddell for SIDS is that of an acute severe magnesium deficiency $(2,3)$. We used Dr. Caddell's recommendation which stated that bone was the tissue of choice to determine magnesium status under these conditions (3). We reported that we found no difference in the magnesium content of ribs from SIDS and non-SIDS infants and, coincidently, for what it is worth, no difference in the magnesium content of kidney cortex and lung tissues, and an elevated level of magnesium in the liver tissues of SIDS. Although an elevation of liver magnesium may not rule out deficiency, in the context of our other results, we find it hard to view this as supportive of a magnesium deficiency because many other possible explanations exist, including a chance difference.

The suggestion of a congenital magnesium deficiency is interesting. But, because magnesium is actively transported across the placenta $(1,5)$, the fetus receives magnesium even at the expense of the mother. Only in moderately severe maternal deficiency would the fetus be deprived. Indeed, with more mild maternal deficiency one would expect to find no decrease in bone magnesium as reported by Dr. Caddell or any other measurement of magnesium and the use of the term "congenital magnesium deficiency" under those conditions is a misnomer. When we extrapolate the linear regression line of rib magnesium versus age back to the time of birth, it appears that the magnesium content of the SIDS ribs was very similar (3887 versus $3873 \mu \mathrm{g} /$ g) to the non-SIDS ribs.

The study of Cerklewski (4), cited by Dr. Caddell, provides some interesting information on the effect of moderate maternal magnesium deficiency on the tissue lead content of offspring. Dr. Cerklewski states, however, that it would be unwise to extrapolate the findings of this study to human lead toxicity. In this study, rat dams received up to $3600 \mu \mathrm{g} / \mathrm{d} \mathrm{Pb}$ during pregnancy and up to $7200 \mu \mathrm{g} / \mathrm{d} \mathrm{Pb}$ during lactation. The estimated daily lead intake of a breast-fed human infant is about $40 \mu \mathrm{g}$ and the estimated daily lead intake for an adult human is about 300 $\mu \mathrm{g}(10)$. Dr. Caddell states that Dr. Cerklewski's results are similar to ours: "no change in soft tissue magnesium, a small $(5 \%)$ decrease in bone magnesium,... ." Again, this is with a moderately magnesium-deficient diet. The SIDS bone magnesium in our study is $14 \mu \mathrm{g} / \mathrm{g}$ less than non-SIDS bone and this represents a difference of less than $0.4 \%$. Whether or not in humans, there could exist a state of maternal magnesium deficiency great enough to increase maternal blood lead (and therefore increase infant blood and tissue lead) but of mild enough degree to spare the infant from magnesium deficiency is unknown. The differential handling by the human placenta of magnesium (active transport) and lead (free diffusion) indeed make this a possibility.

In response to the question of socioeconomic status, the majority of both SIDS and non-SIDS cases were classified as being in a low socioeconomic group and environmental factors were quite similar although this was not specifically addressed in this study. We were well aware before starting the study of the similarity of the epidemiology of lead exposure and infant death in general, particularly SIDS. As clearly stated in the paper, the increased lead levels in SIDS could represent merely this epidemiologic overlap. Much greater study is needed to provide any physiologic link between lead and SIDS. The environmental factors relative to increased lead exposure in infants in general are being addressed in another publication.

Although we feel justified in stating that we found no evidence of an acute magnesium deficiency (the model initially put forth by Dr. Caddell) in the SIDS victims we studied, we would welcome Dr. Caddell's hypothesis of a mechanism by which a subtle chronic magnesium deficiency would cause sudden death in infants and her suggestions for proving or disproving such a hypothesis.

\section{REFERENCES AND NOTES}

1. Aikawa. J. K. and Burns, P. D.: Placental transfer and fetal tissue uptake of ${ }^{28} \mathrm{Mg}$ in the rabbit. Proc. Soc. Exp. Biol. Med., 105: 95 (1960).

2. Caddell. J. L.: Magnesium deprivation in sudden unexpected infant death. Lancet, 2: 258 (1972).

3. Caddell, J. L. and Scheppner, R.: The postmortem diagnosis of magnesium deficiency: Studies in an animal model for the human infant. J. Forensic Sci.. 23: 335 (1978).

4. Cerklewski, F. L.: Influence of maternal magnesium deficiency on tissue lead content of rats. J. Nutr., 1/3: 1443 (1983).

5. Dancis, J.. Springer, D., and Cohlan. S. Q.: Fetal homeostasis in maternal malnutrition: I. Magnesium deprivation. Pediatr. Res., 55: 131 (1971)

6. Erickson, M. M., Poklis. A., Gantner, G. E.. Dickinson, A. W., and Hillman, L. S.: Tissue mineral levels in victims of sudden infant death syndrome. I. Toxic metals-cadmium and lead. Pediatr. Res., 17: 779 (1983).

7. Erickson. M. M.. Poklis, A., Gantner, G. E., Dickinson. A. W., and Hillman, L. S.: Tissue mineral levels in victims of sudden infant death syndrome. II. Essential minerals: copper, zinc, calcium, and magnesium. Pediatr. Res., 17: 784 (1983).

8. Probst. G. S.: Cadmium: absorption, distribution and excretion in mammals. In: J. H. Mennear: Cadmium Toxicity. p. 29 (Marcel Dekker, Inc., New York. 1979).

9. Rabinowitz, M. B., Wetherill, G. W., and Kopple, J. D.: Kinetic analysis of lead metabolism in healthy humans. J. Clin. Invest., 58: 260 (1976).

10. Tsuchiya, K.: Lead. In: L. Friberg, G. F. Nordberg, and V. B. Vouk: Handbook of the Toxicology of Metals. p. 451 (Elsevier/North Holland Biomedical Press. New York, 1979).

\section{Letter to the Editor}

ANDREW J. MCPHEE AND UMA R. KOTAGAL

Department of Pediatrics, Newborn Division, University of Cincinnati Medical Center, Cincinnati, OH USA

The concept of autoregulation of cerebral blood flow (CBF) dictates the $\mathrm{CBF}$ is independent of blood pressure over the range of the autoregulatory plateau. To prove abolition of autoregulation of CBF under a particular physiologic condition, three major criteria must be satisfied: $I$ ) the physiologic condition or variable under study should be rigorously controlled; 2) the range of blood pressures studied must be within the known autoregulatory limits of the cerebral system under study; and 3) all other known determinants of CBF should be maintained constant. In our opinion, the recent study by Tweed et al. ("Arterial oxygenation determines autoregulation of cerebral blood flow in the fetal lamb." Pediatr. Res., 17: 246, 1983), fails to satisfy the first two of these criteria, and the conclusions are therefore suspect.

First. Jones et al. $(1,2)$ have demonstrated clearly that arterial oxygen $\left(\mathrm{O}_{2}\right)$ content is a potent determinant of $\mathrm{CBF}$ in the same chronically catheterized fetal lamb model. Indeed, CBF was shown to be inversely related to arterial $\mathrm{O}_{2}$ content, especially when less than $8 \mathrm{ml} / \mathrm{dl}$. Tweed et al., do not measure $\mathrm{O}_{2}$ content, but take an average calculated arterial $\mathrm{O}_{2}$ saturation of $57 \%$ and an average hemoglobin of $11.5 \mathrm{~g} / \mathrm{dl}$ to calculate an arterial $\mathrm{O}_{2}$ content of $8-9 \mathrm{ml} / \mathrm{dl}$. They then dismiss $\mathrm{O}_{2}$ content as a factor because this figure is "above the level at which hypoxic hyperemia is observed." By their design, however, the $\mathrm{O}_{2}$ saturation in the hypoxic group is less than $57 \%$ (range, 22-57\%). In addition, there are marked differences in $\mathrm{O}_{2}$ saturation during the blood pressure manipulations; thus, if the arterial $\mathrm{O}_{2}$ contents of the hypoxic group place them within the range of "hypoxic hypermia," then the changes in $\mathrm{O}_{2}$ contents during the manipulations 
would be expected to contribute significantly to changes in flow. In fact, the decrease in flow seen in the hypoxic group after hypotension could be explained by the marked improvements in oxygenation which accompanied the hypotension.

Second, the results of the studies in their normoxic group establish an autoregulatory plateau between pressure means of 41-62 torr for this cerebral vascular system. But in their hypoxic hypertensive study, the mean arterial blood pressure (MABP) was elevated to 73 torr, a level which exceeds the upper limit of the autoregulatory plateau. In addition, the control MABP for the hypoxic group at the beginning of the study (i.e., before the hypotensive study period) was 66 torr, another value in excess of the upper limit of the established plateau. Overall, the apparent linear relationship between flow and blood pressure as shown in Figure 1 in the Tweed et al. paper could be explained by improved oxygenation during hypotension, and the fact that the upper limit of autoregulation was exceeded during hypertension.

There are several other points which deserve comment. The first of these is that this study does not appear to have been designed prospectively in that the hypoxic study group was arbitrarily selected on the basis of an arterial $\mathrm{O}_{2}$ saturation of less than $57 \%, 24-48 \mathrm{hr}$ after surgery. The question of why these animals were hypoxic is not addressed. Second, comparison of the control measurements of the hypoxic group in Table 1, and for the same group in Table 3 (see column 1) shows clear differences in many of the variables. Both sets of measurements are said to be taken under control conditions, hence these differences cast doubt on the physiologic stability of this study group. Finally, from the presented results, it appears that five flow estimations were made in the majority of animals. It is difficult to envisage how these five measurements could be made using only three microsphere species.

If autoregulation of $\mathrm{CBF}$ in sick newborn infants is impaired, as suggested by the studies of Lou et al. (3) and Milligant (4), then one would expect to find impairment in animal models exposed to similar physiologic stresses. To date, this does not appear to be the case, except perhaps with profound fetal asphyxia (5). Because this question has important implications in the clinical management of premature infants, it deserves rigorous study. In view of the objections raised above, we feel that the study by Tweed $e t$ al. fails to resolve the issue of the relationship between autoregulation and arterial oxygenation, and that therefore, their prediction that "CBF is likely to be pressure passive in most newborns" seems unjustified.

\section{REFERENCES AND NOTES}

1. Jones, D. M., Sheldon, R. E., Peeters, L. L., Makowski, E. L., and Meschia, G.: Regulation of cerebral blood flow in the ovine fetus. Amer. J. Physiol,, 235: H162 (1978).

2. Jones, D. M., Taystman, R. J., Simmons, M. A., and Molteni, R. A.: Effects of changes in arterial oxygen content on cerebral blood flow in the lamb. Amer. J. Physiol., 240: H209 (1981).

3. Lou, H. C., Lassen. N. A., and Friis-Hansen, B.: Impaired autoregulation of cerebral blood flow in the distressed newborn infant. J. Pediatr. 94: 118 (1979).

4. Milligan. D. W. A.: Failure of autoregulation and intraventricular hemorrhage in preterm infants. Lancet, $1: 896$ (1980).

5. Lou. H. C., Lassen, N. A., Tweed, W. A., Johnson, G., Jones, M., and Palahniuk, R. J.: Pressure passive cerebral blood flow and breakdown of the blood-brain barrier in experimental fetal asphyxia. Acta Paediatr. Scand., 68: 57 (1979) 